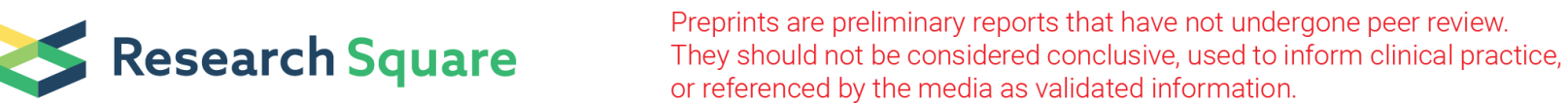

\section{Risk Factors and Clinical Prognosis of Hyperbilirubinemia After Off-pump Coronary Artery Bypass Grafting}

\section{Yingdi Gao}

Beijing Chaoyang Hospital https://orcid.org/0000-0002-4776-6906

\section{Dongjie Li}

Beijing Chaoyang Hospital

\section{Honghong Dong}

Beijing Chaoyang Hospital

\section{Yulin Guo}

Beijing Chaoyang Hospital

\section{Yuanshu Peng}

Beijing Chaoyang Hospital

\section{Yan Liu}

Beijing Chaoyang Hospital

Pixiong Su ( $\square$ supixiong1130@163.com )

Chao-Yang Hospital, Capital Medical University

\section{Research article}

Keywords: Off-pump coronary artery bypass grafting, Hyperbilirubinemia, Risk factors, Prognosis

Posted Date: July 1st, 2021

DOI: https://doi.org/10.21203/rs.3.rs-658229/v1

License: (1) This work is licensed under a Creative Commons Attribution 4.0 International License. Read Full License 


\section{Abstract}

Background: The incidence of hyperbilirubinemia after off-pump coronary artery bypass grafting (OPCAB) is unclear. This study aimed at retrospectively analyzing the incidence and character of perioperative hyperbilirubinemia in patients undergoing $\mathrm{OPCAB}$, to analyze the independent risk factors, to identify the correlation with adverse events and mortality, and to explore the management strategy of perioperative hyperbilirubinemia.

Methods: Clinical data for 416 patients (314 males and 102 female), who had been subjected to off-pump coronary artery bypass grafting in the Department of Cardiac Surgery, Beijing Chaoyang Hospital from December, 2016 to March, 2019 were recorded. Hyperbilirubinemia was defined as serum total bilirubin $\geq 34.2$ $\mu \mathrm{mol} / \mathrm{L}$ within 5 days after surgery. Based on the occurrence of hyperbilirubinemia, patients were divided into the normal serum total bilirubin group and the hyperbilirubinemia group. Perioperative variables between the two groups were compared by univariate logistic regression analysis. Multivariate logistic regression analysis was used to analyze variables with statistical significance. Then, we determined the independent risk factors for hyperbilirubinemia after OPCAB. Moreover, incidences of adverse events, length of ICU stay, time of mechanical ventilation and mortality rates between the two groups were compared.

Results: Thirty two of 416 patients were found to exhibit postoperative hyperbilirubinemia. The incidence rate was $7.7 \%$. Based on univariate regresssion analysis, differences in gender, preoperative total bilirubin levels, perioperative IABP implantation, perioperative blood transfusion between the two groups were significant. Multivariate logistic regression analysis revealed that elevated preoperative serum total bilirubin levels $(\mathrm{OR}=1.241, p<0.001)$, perioperative blood transfusion $(\mathrm{OR}=0.237, p=0.002)$ and perioperative IABP implantation $(\mathrm{OR}=0.238, p=0.003$ ) were independent risk factors for hyperbilirubinemia after OPCAB. Compared to the normal bilirubin group, incidences of new acute renal failure, continuous renal replacement therapy, perioperative myocardial infarction, pulmonary infection, multiple organ dysfunction syndrome and in-hospital mortality in the hyperbilirubinemia group were significantly increased.

Conclusions: Perioperative hyperbilirubinemia is associated with adverse events and mortality. In clinical practice, changes in serum total bilirubin levels among patients undergoing OPCAB should be routinely monitored, and active as well as early interventions in patients with risk factors performed. In this manner, postoperative complications can be reduced, thereby improving patient prognosis.

\section{Background}

Hyperbilirubinemia is a common complication after off-pump coronary artery bypass grafting (OPCAB). It has been reported that postoperative hyperbilirubinemia is significantly related with poor patient prognosis. Perioperative hyperbilirubinemia patients have been shown to exhibit prolonged mechanical ventilation time, longer hospital stay, and significantly increased complications as well as hospital mortality rates(1-8).

However, a limited number of studies have elucidated on the risk factors of hyperbilirubinemia after CABG. Mastoraki et al. and Sharma et al. have reported on hyperbilirubinemia after cardiac surgery, but did not distinguish between surgical types, the presence or absence of cardiopulmonary bypass (CPB) and other factors. Therefore, clinical implications of their studies are limited $(1,2)$. Nishi et al. and Chen et al. reported hyperbilirubinemia after valve and large vessel surgeries, respectively $(9,10)$. However, to the best of our 
knowledge, studies have not reported on hyperbilirubinemia after OPCAB. Given that on-pump and off-pump CABG have completely different pathophysiological processes, and OPCAB is being performed in many cardiac surgical centers, we retrospectively analyzed incidences and risk factors for hyperbilirubinemia after OPCAB, as well as its correlation with postoperative adverse events, so as to guide clinical practice, promote surgical quality and improve prognostic outcomes.

\section{Materials And Methods}

\section{Study population and patients selection}

A total of 416 patients undergoing OPCAB in our center from December 2016 to March 2019 were enrolled in this study. All patients were diagnosed with coronary heart disease by coronary angiography before operation. Diagnostic criteria of hyperbilirubinemia: highest serum total bilirubin $\geq 34.2 \mu \mathrm{mol} / \mathrm{L}$ within 5 days after surgery.

Exclusion criteria: i. Serious deficiency of clinical data; ii. Emergency CABG; iii. Previous history of cardiac surgery; iv. CABG performed under cardiopulmonary bypass; v. Patients subjected to valve surgery or other cardiac surgical procedures, including one-step hybrid surgery with $\mathrm{PCl}$, at the same time; vi. Preoperative serum total bilirubin levels $\geq 34.2 \mu \mathrm{mol} / \mathrm{L}$.

\section{Data collection}

Through a review of medical records, the obtained clinical data were: age, gender, body mass index (BMI), smoking history, general complications, cardiac function and NHYA classification, left ventricular end diastolic diameter (LVEDD), left atrial diameter (LAD), left ventricle ejection fraction (LVEF), latest laboratory examination results including hemoglobin levels, albumin levels, liver and kidney functions, operation time, intraoperative blood loss, perioperative blood transfusion, and IABP implantation among others (Table 1). Serum total bilirubin, direct bilirubin and indirect bilirubin levels were recorded on the first day and on the thirty $\sim$ fifth day after surgery. 
Table 1

Baseline characteristics and perioperative details of patients in both groups

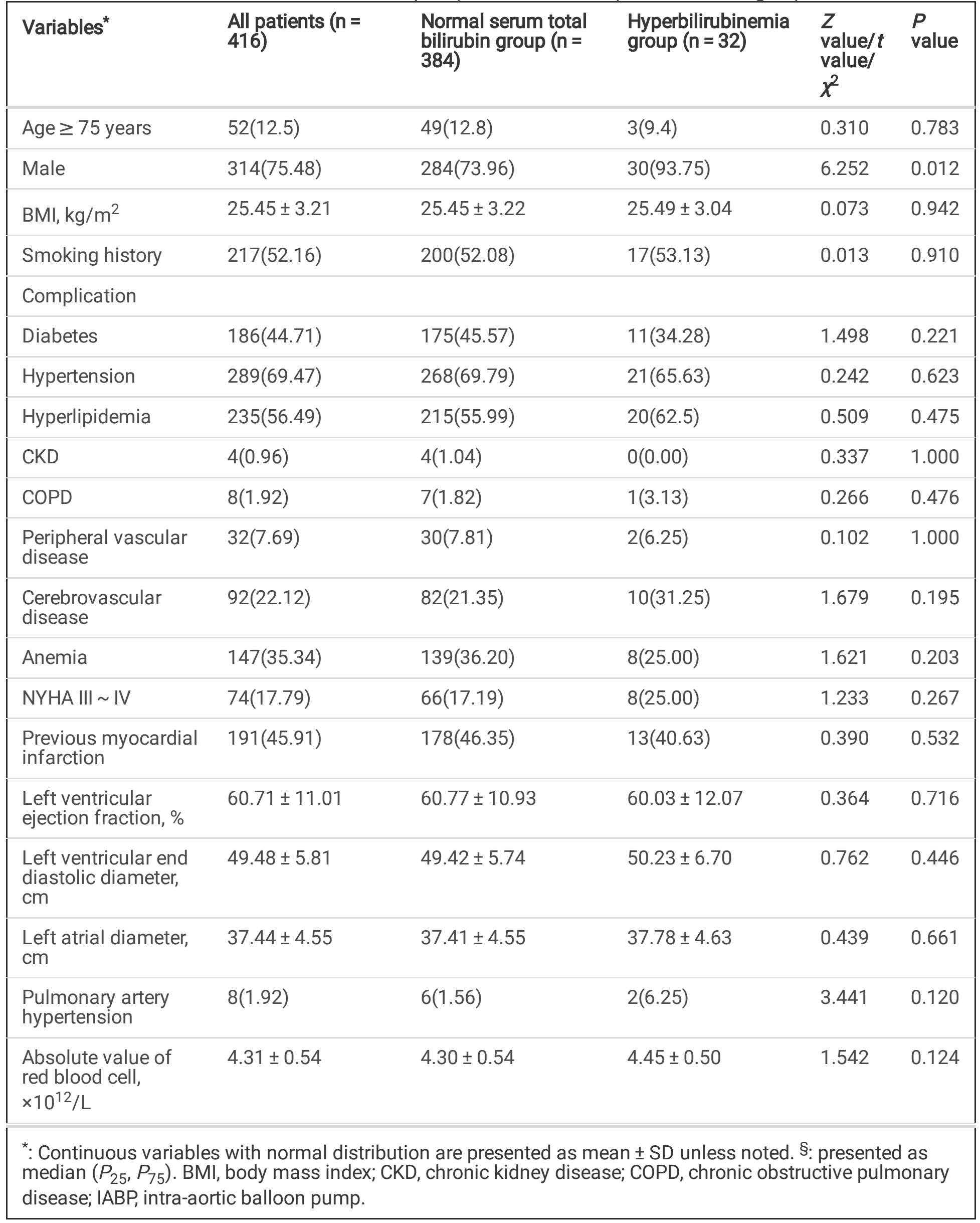




\begin{tabular}{|c|c|c|c|c|c|}
\hline Variables ${ }^{*}$ & $\begin{array}{l}\text { All patients }(n= \\
416)\end{array}$ & $\begin{array}{l}\text { Normal serum total } \\
\text { bilirubin group }(n= \\
384)\end{array}$ & $\begin{array}{l}\text { Hyperbilirubinemia } \\
\text { group }(n=32)\end{array}$ & $\begin{array}{l}Z \\
\text { value/ } t \\
\text { value/ } \\
\chi^{2}\end{array}$ & $\begin{array}{l}P \\
\text { value }\end{array}$ \\
\hline Albumin, $\mathrm{g} / \mathrm{L}$ & $39.72 \pm 3.41$ & $39.71 \pm 3.38$ & $39.87 \pm 3.78$ & 0.036 & 0.971 \\
\hline $\begin{array}{l}\text { Serum creatinine, } \\
\mu \mathrm{mol} / \mathrm{L} \S\end{array}$ & $73.70(63.10,87.25)$ & $73.55(62.60,87.08)$ & $76.75(66.75,88.30)$ & 1.096 & 0.273 \\
\hline $\begin{array}{l}\text { Abnormal liver } \\
\text { enzymes }\end{array}$ & $58(13.94)$ & $50(13.02)$ & $8(25.00)$ & 3.533 & 0.105 \\
\hline $\begin{array}{l}\text { Serum total } \\
\text { bilirubin, } \mu \mathrm{mol} / \mathrm{L}\end{array}$ & $12.41 \pm 5.10$ & $11.92 \pm 4.52$ & $18.28 \pm 7.57$ & 5.155 & 0.000 \\
\hline $\begin{array}{l}\text { Operation time, } \\
\text { hours }\end{array}$ & $3.89 \pm 0.71$ & $3.87 \pm 0.71$ & $4.01 \pm 0.76$ & 0.581 & 0.561 \\
\hline $\begin{array}{l}\text { Intraoperative blood } \\
\text { loss, ml }\end{array}$ & $465.79 \pm 176.90$ & $463.33 \pm 174.40$ & $495.31 \pm 205.32$ & 0.522 & 0.601 \\
\hline $\begin{array}{l}\text { Perioperative blood } \\
\text { transfusion }\end{array}$ & 162(38.94) & 144(37.5) & 18(56.3) & 4.367 & 0.037 \\
\hline $\begin{array}{l}\text { Perioperative IABP } \\
\text { implantation }\end{array}$ & $101(24.28)$ & $87(22.66)$ & $14(43.8)$ & 7.149 & 0.008 \\
\hline
\end{tabular}

\section{Outcomes and definitions}

Perioperative events including cumulative time of mechanical ventilation, occurrence of perioperative myocardial infarction, new onsets of acute renal failure, new onsets of pulmonary infection, occurrence of other related complications, incidences of multiple organ dysfunction syndrome (MODS) and in-hospital mortality were also recorded (Table 2). The definition of AKI were based on the 2012 Kidney Disease Improving Global Outcomes (KDIGO) guideline. 
Table 2

Comparisons of postoperative adverse events and mortality between the two groups

\begin{tabular}{|c|c|c|c|c|c|}
\hline Variables* & All patients $(n=416)$ & $\begin{array}{l}\text { Normal serum total } \\
\text { bilirubin group }(n= \\
384)\end{array}$ & $\begin{array}{l}\text { Hyperbilirubinemia } \\
\text { group }(n=32)\end{array}$ & $\begin{array}{l}Z \text { value/ } \\
\chi^{2}\end{array}$ & $\begin{array}{l}P \\
\text { value }\end{array}$ \\
\hline $\begin{array}{l}\text { New onset } \\
\text { of acute } \\
\text { renal failure }\end{array}$ & $10(2.40)$ & $7(1.82)$ & $3(9.38)$ & 7.181 & 0.034 \\
\hline $\begin{array}{l}\text { Continuous } \\
\text { renal } \\
\text { replacement } \\
\text { therapy }\end{array}$ & $5(1.20)$ & $2(0.52)$ & $3(9.38)$ & 19.501 & 0.004 \\
\hline $\begin{array}{l}\text { Cumulative } \\
\text { mechanical } \\
\text { ventilation } \\
\text { time, hours } \$\end{array}$ & $17.00(17.00,22.00)$ & $17.00(17.00,21.00)$ & $18.00(17.00,98.00)$ & 1.651 & 0.099 \\
\hline $\begin{array}{l}\text { Re- } \\
\text { intubation }\end{array}$ & $14(3.37)$ & $11(2.87)$ & $3(9.38)$ & 3.850 & 0.084 \\
\hline $\begin{array}{l}\text { ICU stay, } \\
\text { hours } \$\end{array}$ & $116.00(72.00,170.00)$ & $116.00(72.00,168.75)$ & $131.50(70.50,222.75)$ & 0.846 & 0.398 \\
\hline $\begin{array}{l}\text { Perioperative } \\
\text { myocardial } \\
\text { infarction }\end{array}$ & $27(6.49)$ & $22(5.72)$ & $5(15.63)$ & 4.766 & 0.046 \\
\hline $\begin{array}{l}\text { New onset } \\
\text { of } \\
\text { pulmonary } \\
\text { infection }\end{array}$ & $25(6.01)$ & $17(4.43)$ & $8(25.00)$ & 22.133 & 0.000 \\
\hline $\begin{array}{l}\text { New onset } \\
\text { of stroke }\end{array}$ & $7(1.68)$ & $6(1.56)$ & $1(3.13)$ & 0.436 & 0.431 \\
\hline $\begin{array}{l}\text { New onset } \\
\text { of atrial } \\
\text { fibrillation }\end{array}$ & $42(10.10)$ & $36(9.38)$ & $6(18.75)$ & 2.860 & 0.118 \\
\hline MODS & $3(0.72)$ & $1(0.26)$ & $2(6.25)$ & 14.801 & 0.016 \\
\hline $\begin{array}{l}\text { In-hospital } \\
\text { mortality }\end{array}$ & $11(2.64)$ & $7(1.82)$ & $4(12.50)$ & 13.081 & 0.007 \\
\hline $\begin{array}{l}\text { Hospital } \\
\text { stay, days§ }\end{array}$ & $22.00(19.00,27.00)$ & $22.00(19.00,27.00)$ & $22.50(18.00,29.75)$ & 0.048 & 0.962 \\
\hline
\end{tabular}

\section{Surgical procedure}

Surgical procedures were performed by the same group of surgeons. A total of 389 patients were subjected to median sternotomy, 26 patients were subjected to endoscope assisted mini incision while 1 patient was 
subjected to the left anterolateral mini incision. The left internal mammary artery (LIMA) to left anterior descending artery (LAD) bridge was routinely selected. For the other coronary arterial grafts, there were 402 cases of great saphenous vein bridge, 6 cases of radial arterial bridge, 5 cases of great saphenous vein + radial arterial bridge and 3 cases of right breast arterial bridge. The average quantity of bridges was $2.86 \pm 0.58$, while the average operation time was $3.88 \pm 0.71$ hours.

\section{Statistical analysis}

Statistical analyses were performed using the SPSS 26.0 software. The Shapiro Wilk test was used to test the normality of measurement data. Measurement data of normal distributions were expressed as means \pm standard deviation, and independent sample t-test was used for between group comparisons. Measurement data of nonnormal distributions were presented as $M\left(P_{25}, P_{75}\right)$, and the non-parametric Mann-Whitney $U$ test was used for group comparisons. Count data were expressed as frequencies (percentage), and Pearson chi-square test or Fisher's exact test were used for between group comparisons. For variables that exhibited significant differences in univariate analysis, the multivariate logistic regression analysis model was used to obtain further conclusions. $p \leq 0.05$ was considered statistically significant.

\section{Results}

\section{Baseline characteristics}

A total of 416 patients, including 314 males $(75.48 \%)$ and 102 females $(24.52 \%)$ undergoing OPCAB were enrolled in this study. Their average age was $64.16 \pm 8.83$ years.

Cases of postoperative hyperbilirubinemia were found in 32 patients $(7.7 \%)$. Among them, cases of severe hyperbilirubinemia (serum total bilirubin $\geq 51.3 \mu \mathrm{mol} / \mathrm{L}$ ) were reported in 6 patients $(1.4 \%$ ). In the hyperbilirubinemia group, the percentage of direct bilirubin to total bilirubin was $36.12 \% \pm 6.32 \%$ before surgery, and $51.46 \% \pm 19.98 \%$ after surgery. Statistically significant difference was shown $(p<0.001)$. There were 23 patients (71.88\%) whose direct bilirubin levels were elevated. Among them, 4 patients died. There were 9 patients (28.13\%) whose indirect bilirubin levels were elevated, and none of them died.

\section{Logistic regression analysis for risk factors of AKI after HCR}

Based on univariate regresssion analysis, the proportion of males in the hyperbilirubinemia group was far higher than that of the normal serum bilirubin group $(p=0.012)$. Preoperative total bilirubin levels, the incidence of perioperative IABP implantation and perioperative blood transfusion in the hyperbilirubinemia group were significantly increased than those in the normal serum total bilirubin group $(p<0.05)$. There were no significant differences in age, BMI, smoking, basic diseases, cardiac function classification, echocardiographic indices and laboratory examination indices between the two groups $(p>0.05)$ (Table 1$)$.

Multivariate logistic regression analysis revealed that elevated serum total bilirubin levels ( $O R=1.241,95 \% \mathrm{Cl}$ : $1.156 \sim 1.333, p<0.001)$, perioperative IABP implantation ( $\mathrm{OR}=0.238,95 \% \mathrm{Cl} .0 .094 \sim 0.604, p=0.003)$, perioperative blood transfusion ( $\mathrm{OR}=0.237,95 \% \mathrm{Cl}$ : $0.095 \sim 0.590, p=0.002)$ were independent risk factors for hyperbilirubinemia after OPCAB. 
In addition, incidences of new onset of acute renal failure, continuous renal replacement therapy, perioperative myocardial infarction, new onset of pulmonary infection, MODS and in-hospital mortality levels were significantly elevated in the hyperbilirubinemia group $(p<0.05)$, as shown in Table 2 . There were no significant differences in cumulative mechanical ventilation time, re-intubation, new onset of stroke, new onset of atrial fibrillation, ICU stay and total hospital stay between the two groups $(p>0.05)$.

\section{Discussion}

Hyperbilirubinemia is a common complication after OPCAB. However, there is no consensus on the diagnostic criteria of perioperative hyperbilirubinemia. Previous studies set it at the upper limit of normal value to 51.3 $\mu \mathrm{mol} / \mathrm{L}$. In these studies, incidences of hyperbilirubinemia after CABG were significantly different $(13 \% \sim 51 \%)(4$, 6). In most studies, elevated serum total bilirubin levels $\geq 34.2 \mu \mathrm{mol} / \mathrm{L}$ within 5 days after operation were defined as hyperbilirubinemia $(2,4,5)$. This diagnostic standard is also used in this study. In this study, the incidence of hyperbilirubinemia after OPCAB was found to be $7.7 \%$, while the incidence of severe hyperbilirubinemia was $1.4 \%$, which were less than those reported in previous studies. This difference may be attributed to the strict exclusion criteria of our study.

Regarding the nature of postoperative hyperbilirubinemia, most patients $(71.88 \%)$ exhibited elevated direct bilirubin levels, which is in agreement with previous reports $(1,10)$. Nishi et al. reported that patients with elevated direct bilirubin levels were more likely to have higher mortality rates and worse prognostic outcomes than patients with elevated indirect bilirubin levels(10). This difference was also found in this study (17.39\% for direct bilirubin vs. $0 \%$ for indirect bilirubin, $p=0.303$ ), although the difference was not significant. In contrast, Mastoraki et al. reported that patients with elevated indirect bilirubin levels have worse prognostic outcomes, which may be due to the longer operation time and extracorporeal circulation time, larger intraoperative blood loss and perioperative blood transfusion, resulting in increased hemolytic hyperbilirubinemia(1).

In this study, in the hyperbilirubinemia group, 19 patients (59.38\%) had direct bilirubin / total bilirubin ratio > 50\%, 10 patients (31.25\%) had direct bilirubin / total bilirubin ratio between $20 \%$ and $50 \%, 3$ patients (9.38\%) had direct bilirubin / total bilirubin ratio $<20 \%$, while 5 patients $(15.63 \%)$ had elevated liver enzyme levels, implying that the main cause of hyperbilirubinemia after OPCAB was intrahepatic cholestasis, followed by hepatocyte damage, and hemolysis in a few patients. Which is in agreement to the conclusion of Mastoraki et al(1).

Univariate logistic regression analysis revealed that there were significant differences in gender, preoperative total bilirubin level, perioperative IABP implantation and perioperative blood transfusion between the two groups. Preoperative serum total bilirubin levels $(\mathrm{OR}=1.241, p<0.001)$, perioperative IABP implantation $(\mathrm{OR}=0.238, p=$ 0.003 ) and perioperative blood transfusion ( $\mathrm{OR}=0.237, p=0.002)$ were found to be independent risk factors for hyperbilirubinemia after OPCAB.

Perioperative IABP implantation ensures blood supply to the heart and brain, therefore, it is bound to reduce blood supply to the liver, resulting in insufficient liver perfusion, ischemia and hypoxia of liver cells, triggering atrophy and apoptosis, as well as inhibition of liver functions to varying degrees $(1,11)$. Therefore, all stages of the bilirubin circulatory pathway, including albumin transport, hepatocyte uptake, carrier protein transport and related enzyme catalysis, are blocked by inhibition of hepatocyte function, resulting in continuous accumulation of bilirubin in serum $(7,12)$. At the same time, functions of Kupffer cells of macrophages in hepatic sinuses are 
inhibited, while their roles in clearing aging, damaged red blood cells, as well as clearing microorganisms and poisons from the intestinal tract are weakened, resulting in pathophysiological changes such as bilirubin stasis and intestinal endotoxemia $(13,14)$. The former aggravates inhibition of the roles of Kupffer cells, while the latter can damage the intestinal mucosal barrier through a series of actions and promote endotoxin absorption, thereby leading to a vicious cycle. Endotoxin accumulation may cause hepatocyte injury and induce apoptosis through immune cell activation, induction of the production of free oxygen radicals, secretion of cytokines and inflammatory mediators, inhibiting bilirubin circulation, and finally, by leading to the formation of hepatocyte hyperbilirubinemia(7, 12-14).

Lockey et al. and Wang et al. reported that elevated indirect bilirubin levels were the main causes of postoperative hyperbilirubinemia $(6,11)$, implying that hemolysis is an important factor in hyperbilirubinemia occurrence and development. Massive intraoperative and early postoperative blood transfusion, exceeding treatment threshold of the liver with functional inhibition, and hemolysis of red blood cells in stored blood can lead to massive accumulation of bilirubin, resulting in postoperative hyperbilirubinemia(15). Mathie et al. reported that massive blood transfusion may cause microthrombosis, elevated free radical levels and disorders of liver blood flow, further aggravating liver injury and forming hyperbilirubinemia(7). Moreover, An et al. proposed that prolonged operation time is an independent risk factor for postoperative hyperbilirubinemia(8), implying that elevated tissue oozing and bleeding associated with prolonged operation time, intraoperative destruction and loss of red blood cells and coagulation factors may be some of the involved mechanisms(4). There were no significant differences in operation time between the two groups, however, intraoperative and early postoperative blood transfusion was an independent risk factor for postoperative hyperbilirubinemia.

Most studies were positive about the correlation between hyperbilirubinemia and postoperative complications as well as with adverse events(3, 5, 10-12,16-18). Hyperbilirubinemia after cardiac surgery (especially after cardiopulmonary bypass) is a risk factor for postoperative respiratory $(8)$, circulatory $(12,18)$, urinary $(19,20)$, gastrointestinal complications(21) and hospital mortality. In this study, incidences of pulmonary infection, new acute renal failure, continuous renal replacement therapy, perioperative myocardial infarction and other related complications in the hyperbilirubinemia group were elevated, while incidences of MODS and hospital mortality were higher than those of the normal serum total bilirubin group, with statistically significant differences.

The mechanisms through which hyperbilirubinemia leads to complications and poor prognosis are complex, and have not been fully elucidated. Elevated bilirubin concentrations can trigger cell oxidative stress, induce apoptosis, and participate in a variety of pathological processes, including respiratory dysfunction, thrombocytopenia(19), renal tubular epithelial cell damage(19), neural cell differentiation and myelination inhibition(23). In addition, persistent hyperbilirubinemia is only a manifestation of a potential disease, such as persistent low cardiac output syndrome, rather than a direct cause of death(2).

Prolonged bilirubin peak time in patients with hyperbilirubinemia is an independent predictor of death. Chen et al., Sharma et al. and others reported that early jaundice after cardiac surgery is mostly transient, and is mainly caused by surgical strikes, while late and persistent hyperbilirubinemia (lasting for more than 5 days after operation) may be related to cardiac failure $(12,17,18)$ or septicemia, leading to acute liver failure, with rapidly elevated in-hospital mortality rates $(2,11,20)$. Farag et al. reported that patients with bilirubin peak time more than 3.5 days and peak value exceeding $91.5 \mu \mathrm{mol} / \mathrm{L}$ had significantly higher mortality rates while patients with bilirubin peak value exceeding $436.1 \mu \mathrm{mol} / \mathrm{L}$ had mortality rates above $99 \%(16)$. However, these conclusions 
lack support from molecular biology experiments. Studies should aim at elucidating the pathophysiological significance of bilirubin at the molecular level.

This study has certain significance for clinical practice. First, for patients with elevated serum total bilirubin levels before OPCAB, potential causes should be investigated and corresponding therapy for the primary disease administered. Second, the experience level of the surgical team should be improved to reduce iatrogenic complications of IABP implantation, decrease intraoperative bleeding, shorten operation time, so as to suppress the chances of perioperative hyperbilirubinemia caused by iatrogenic factors. Third, there is a need to improve the management ability of blood products. For patients with more intraoperative bleeding and a higher possibility of perioperative blood transfusion, restrictive and autologous blood transfusion strategy $(15,24)$ should be adopted. Moreover, active and regular measurements of postoperative serum total bilirubin levels is necessary. For patients with mild elevations of serum total bilirubin, choleretic drugs such as Smectite and Yinzhihuang could be effective; for patients with severe elevations of serum total bilirubin and acute liver failure, artificial liver support system (ALSS), including plasma bilirubin adsorption (PBA), plasma exchange (PE), hemofiltration (HF), hemodialysis (HD) and their combination strategies should be applied, according to the indications. If the progress of hyperbilirubinemia cannot be controlled by the above methods, liver transplantation may be the last chance $(25,26)$.

This study is associated with some limitations. First, as a single center retrospective study, the collection of bilirubin index data is limited to a certain extent. Only the bilirubin peak near the measurement time was recorded. Therefore, false negatives might be in existence. Studies should aim at establishing standardized time points, where serum bilirubin levels among all patients can be continuously and repeatedly measured, so as to reduce the above bias. Second, we did not record factors such as storage time of blood products, IABP mode and duration of use, which may affect the results of this study. Therefore, multicenter prospective randomized controlled trials are need to overcome these biases.

\section{Conclusion}

Perioperative hyperbilirubinemia is associated with adverse events and mortality. Elevated preoperative serum total bilirubin levels, perioperative IABP implantation and perioperative blood transfusion rates are independent risk factors for hyperbilirubinemia after OPCAB. In clinical practice, changes in serum total bilirubin levels among patients undergoing OPCAB should be routinely monitored, and active as well as early interventions in patients with risk factors performed. In addition, technical levels of the surgical team should be continuously improved while perioperative blood management should be strengthened. In this manner, postoperative complications can be reduced, thereby improving patient prognosis.

\section{List Of Abbreviations}

OPCAB, off-pump coronary artery bypass grafting

CABG, coronary artery bypass grafting

$\mathrm{PCl}$, percutaneous coronary intervention

$\mathrm{OR}$, odds ratio

Page 10/13 
$\mathrm{Cl}$, confidence interval

$\mathrm{CPB}$, cardiopulmonary bypass

BMI, body mass index

COPD, chronic obstructive pulmonary disease

LVEF, left ventricle ejection fraction

LVEDD, left ventricular end diastolic diameter

$L A D$, left atrial diameter

IABP, intra-aortic balloon pump

AKI, acute kidney injury

MODS, multiple organ dysfunction syndrome

LIMA to LAD, left internal mammary artery to left anterior descending artery

ICU, intensive care unit

ALSS, artificial liver support system

PBA, including plasma bilirubin adsorption

PE, plasma exchange

HF, hemofiltration

$H D$, hemodialysis

\section{Declarations}

Ethics approval and consent to participate: The authors are accountable for all aspects of the work in ensuring that questions related to the accuracy or integrity of any part of the work are appropriately investigated and resolved. The study was conducted in accordance with the Declaration of Helsinki (as revised in 2013). The study was approved by local research ethics board of Chaoyang Hospital (No.: 2018308) and individual consent for this retrospective analysis was waived.

Consent for publication: Not applicable.

Availability of data and materials: The datasets used or analyzed during the current study are available from the corresponding author on reasonable request.

Competing interests: The authors have no conflicts of interest to declare.

Funding: None

Page $11 / 13$ 
Contributions: YG, DL, HD, YG, YP designed the research. DL, YG(Guo), YL, PS provided study materials and patients. YL, PS also gave administrative support. YG(Gao), DL, HD, YP analyzed and interpreted the patient data. $Y G(G a o)$ was a major contributor in writing the manuscript. All authors read and approved the final manuscript.

Acknowledgements: The authors are grateful for English revision provided by Home for Researchers editorial team $\Downarrow$ www.home-for-researchers.com $\nabla$.

\section{References}

1. Mastoraki A, Karatzis E, Mastoraki S, et al. Postoperative jaundice after cardiac surgery. Hepatobiliary \& pancreatic diseases international : HBPD INT 2007;6:383-7.

2. Sharma $P$, Ananthanarayanan C, Vaidhya N, et al. Hyperbilirubinemia after cardiac surgery: An observational study. Asian Cardiovasc Thorac Ann 2015;23:1039-43.

3. Collins JD, Bassendine MF, Ferner R, et al. Incidence and prognostic importance of jaundice after cardiopulmonary bypass surgery. Lancet (London, England) 1983;1:1119-23.

4. Hosotsubo KK, Nishimura M, Nishimura S. Hyperbilirubinaemia after major thoracic surgery: Comparison between open-heart surgery and oesophagectomy. Critical care (London, England) 2000;4:180-7.

5. Chu CM, Chang CH, Liaw YF, Hsieh MJ. Jaundice after open heart surgery: A prospective study. Thorax 1984;39:52-6.

6. Lockey E, Mcintyre N, Ross DN, Brookes E, Sturridge MF. Early jaundice after open-heart surgery. Thorax 1967;22:165-9.

7. Mathie RT. Hepatic blood flow during cardiopulmonary bypass. Crit Care Med 1993;21:S72-6.

8. An Y, Xiao YB, Zhong QJ. Hyperbilirubinemia after extracorporeal circulation surgery: A recent and prospective study. World J Gastroentero 2006;12:6722-6.

9. Chen X, Bai M, Zhao L, et al. Characteristics and outcomes of Stanford type a aortic dissection patients with severe post-operation hyperbilirubinemia: A retrospective cohort study. J Cardiothorac Surg 2020;15:195.

10. Nishi H, Sakaguchi T, Miyagawa S, et al. Frequency, risk factors and prognosis of postoperative hyperbilirubinemia after heart valve surgery. Cardiology 2012;122:12-9.

11. Wang MJ, Chao A, Huang $\mathrm{CH}$, et al. Hyperbilirubinemia after cardiac operation. Incidence, risk factors, and clinical significance. The Journal of thoracic and cardiovascular surgery 1994;108:429-36.

12. Allen LA, Felker GM, Pocock S, et al. Liver function abnormalities and outcome in patients with chronic heart failure: Data from the Candesartan in Heart Failure: Assessment of Reduction in Mortality and Morbidity (CHARM) program. Eur J Heart Fail 2009;11:170-7.

13. Lin HC, Yang YY, Tsai TH, et al. The relationship between endotoxemia and hepatic endocannabinoids in cirrhotic rats with portal hypertension. J Hepatol 2011;54:1145-53.

14. Lough J, Rosenthall L, Arzoumanian A, Goresky CA. Kupffer cell depletion associated with capillarization of liver sinusoids in carbon tetrachloride-induced rat liver cirrhosis. J Hepatol 1987;5:190-8.

15. Chen QH, Wang HL, Liu L, et al. Effects of restrictive red blood cell transfusion on the prognoses of adult patients undergoing cardiac surgery: A meta-analysis of randomized controlled trials. Critical care (London, England) 2018;22:142. 
16. Farag M, Veres G, Szabó G, et al. Hyperbilirubinaemia after cardiac surgery: The point of no return. ESC heart failure 2019;6:694-700.

17. Chintanaboina J, Haner MS, Sethi A, et al. Serum bilirubin as a prognostic marker in patients with acute decompensated heart failure. The Korean journal of internal medicine 2013;28:300-5.

18. Shinagawa $\mathrm{H}$, Inomata $\mathrm{T}$, Koitabashi $\mathrm{T}$, et al. Prognostic significance of increased serum bilirubin levels coincident with cardiac decompensation in chronic heart failure. Circulation journal : official journal of the Japanese Circulation Society 2008;72:364-9.

19. Naveenkumar SK, Thushara RM, Sundaram MS, et al. Unconjugated Bilirubin exerts Pro-Apoptotic Effect on Platelets via p38-MAPK activation. Sci Rep-Uk 2015;5:15045.

20. Chen X, Bai M, Zhao L, et al. Time to peak bilirubin concentration and advanced AKI were associated with increased mortality in rheumatic heart valve replacement surgery patients with severe postoperative hyperbilirubinemia: A retrospective cohort study. Bmc Cardiovasc Disor 2021;21:16.

21. Mcsweeney ME, Garwood S, Levin J, et al. Adverse gastrointestinal complications after cardiopulmonary bypass: Can outcome be predicted from preoperative risk factors? Anesth Analg 2004;98:1610-7, table of contents.

22. Yuan L, Liao PP, Song HC, et al. Hyperbilirubinemia induces Pro-Apoptotic effects and aggravates renal ischemia reperfusion injury. Nephron 2019;142:40-50.

23. Barateiro A, Domingues HS, Fernandes A, Relvas JB, Brites D. Rat cerebellar slice cultures exposed to bilirubin evidence reactive gliosis, excitotoxicity and impaired myelinogenesis that is prevented by AMPA and TNF-a inhibitors. Mol Neurobiol 2014;49:424-39.

24. Akhlagh SH, Vaziri MTM, Nemati MH, Ashraf H. Changes in liver enzymes and bilirubin after coronary artery bypass grafting using acute normovolemic hemodilution. Acta anaesthesiologica belgica 2011;62:11.

25. Wendon J, Cordoba J, Dhawan A, et al. EASL Clinical Practical Guidelines on the management of acute (fulminant) liver failure. J Hepatol 2017;66:1047-1081.

26. Flamm SL, Yang YX, Singh S, Falck-Ytter YT. American gastroenterological association institute guidelines for the diagnosis and management of acute liver failure. Gastroenterology 2017;152:644-647. 